\title{
AUTORES:
}

\section{JORNADA RADIOATIVA: UM JOGO DE TABULEIRO PARA O ENSINO DE RADIOATIVIDADE}

\author{
Radioactive Journey: A Board Game for Teaching Radioactivity \\ Viaje Radiactivo: Un Juego de Mesa para Enseñar Radioactividad
}

MAIANE FRANÇA DE
SALES ${ }^{1}$
CiD 0000-0001-9928-328X

'Universidade Federal do Acre

(UFAC)

JANAINA SANTOS DA

SILVA ${ }^{2}$

ORCID 0000-0003-1212-8610

${ }^{2}$ Universidade Federal do Acre

(UFAC) aplicados no processo de ensino e aprendizagem de diversos conteúdos, e seus conceitos. Para tanto, esta pesquisa tem o objetivo de investigar as contribuições da utilização de um jogo didático no Ensino do conteúdo de Radioatividade. O jogo "Jornada Radioativa" relacionou os conceitos de Radioatividade, e sua contextualização, e foi aplicado em duas turmas de $2^{\circ}$ ano do ensino médio, no Colégio de Aplicação da Universidade Federal do Acre. Com abordagem metodológica de uma pesquisa qualitativa do tipo exploratória, utilizou-se na produção dos dados um questionário, além da observação direta sobre a aplicação do jogo. Os resultados indicam que a utilização de jogos não é uma prática incomum nas aulas de química dos participantes da pesquisa, porém, é um recurso pertinente a ser inserido, sempre que possível, nas aulas. O jogo "Jornada Radioativa” contribuiu para a compreensão de conceitos relacionados ao conteúdo de Radioatividade, estimulando o desenvolvimento socioemocional dos estudantes, oportunizando um ensino significativo do conteúdo de Química.

Palavras-Chave: Jogo Didático; Radioatividade; Ensino de Química.

Abstract: In the teaching of Chemistry, games are gaining evidence as didactic resources applied to the teaching and learning process of several contents and their concepts. Therefore, this research aims to investigate the contributions of a didactic game used in the Teaching of Radioactivity content. The game "Radioactive Journey" listed the concepts of Radioactivity and its contextualization and we applied it to two classes of 2nd year of high school, in the Application School of the Federal University of Acre. With a methodological approach of a qualitative research of the exploratory type, we used a questionnaire for the data production, in addition to direct observation over the game appliance. The results indicate that the use of games is a common practice to the research participants in the Chemistry classes; however, it is a pertinent resource to insert, whenever possible, in the classes. The game "Radioactive Journey" contributed to the understanding of concepts related to Radioactivity content, stimulating the socio-emotional development of students, providing a meaningful teaching of Chemistry content.

Keywords: Didactic Game; Radioactivity; Chemistry Teaching.

Resumen: En la enseñanza de Química, los juegos están ganando evidencia como recursos didácticos aplicados en el proceso de enseñanza y aprendizaje de diversos contenidos y sus conceptos. Por lo tanto, esta investigación tiene como objetivo investigar las contribuciones del uso de un juego didáctico en la enseñanza de contenidos de la Radiactividad. El juego "Jornada Radioactiva" relató los conceptos de Radioactividad y su contextualización y fue proyectado en dos clases de $2^{\circ}$ año de secundaria, en la Escuela de Aplicación de la Universidad Federal de Acre. Con un enfoque metodológico de una investigación cualitativa de carácter exploratorio, se utilizó un cuestionario en la producción de los datos, además de la observación directa sobre la aplicación del juego. Los resultados indican que la utilización de juegos no es una práctica poco común en las clases de Química de los participantes de la investigación, sin embargo, es un recurso pertinente para ser insertado, siempre que sea posible, en las clases. El juego "Jornada Radioactiva" contribuyó a la comprensión de conceptos relacionados con el contenido de la Radiactividad, estimulando el desarrollo socioemocional de los estudiantes, dando oportunidad para una enseñanza significativa de los contenidos de Química.

Palabras clave: Juego Didáctico; Radioactividad; Enseñanza de La Química.

\section{SHIRANI KAORI HARAGUCHI \\ ORCID 0000-0003-4262-5298}

3 Universidade Federal do Acre (UFAC)

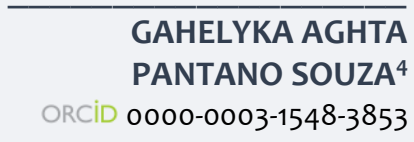

4 Universidade Federal do Acre (UFAC)

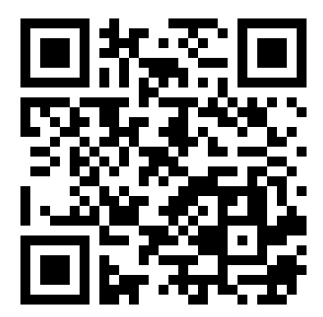

\section{Para citar este artigo:}

SALES, M. F.; et al. Jornada radioativa: um jogo de tabuleiro para o ensino de radioatividade. Revista Eletrônica Ludus Scientiae, Foz do Iguaçu, v. 4, n. 2, p. 74-87, ago./dez., 2020. 


\section{INTRODUÇÃO}

Vivemos em um período marcado pela tecnologia, e pelo acesso imediato, a todo tipo de informação, o acesso a recursos tecnológicos, e a mobilidade que eles oferecem, facilitou e modificou a maneira como as pessoas se relacionam, e se apropriam de novos conhecimentos e informações. A atual geração de estudantes está, cada vez mais, conectada aos acontecimentos no mundo e ao desenvolvimento tecnológico, colocando a escola como mais um espaço de divulgação tecnológica.

A sala de aula, nesse contexto, já não é mais tão estimulante quanto antes. As aulas tradicionais, carregadas de informações faladas, já não são tão significativas, e não conseguem atender a todos os estudantes de uma mesma turma, não que elas sejam ruins, pois parte da atual geração foi formada nesse modelo de ensino, contudo, somente elas já não são mais suficientes para atender a atual geração de estudantes e, nem todos apresentam a mesma facilidade de compreensão, somente, a partir de uma aula expositiva dialogada (VIEIRA, 2014).

No intuito de tornar o processo de ensino e aprendizagem significativo, os professores acabam buscando diferentes recursos didáticos a serem inseridos em suas aulas, como a crescente utilização dos jogos nos espaços formais, e não formais, de ensino. Cada vez mais, essas atividades são inseridas no contexto escolar, seja pela facilidade de adaptação, ou até mesmo pelo baixo custo na produção de alguns jogos já conhecidos. Percebe-se que o professor faz uso desse recurso, no intuito de conseguir um maior envolvimento dos alunos, ao mesmo tempo em que aborda conceitos relativos ao conteúdo trabalhado (LOPES, 2019).

O jogo é, talvez, o recurso mais antigo de que se tenha conhecimento, é natural do ser humano brincar, "a ação de brincar durante a infância e, também na fase adulta é uma maneira significativa de aprendizado" (LAPA; SANTOS, 2018, p. 27). De acordo com Soares (2015), é possível aprender brincando, contudo, é necessário ter cuidado para que a atividade não se torne o contrário, e o aluno brinque de aprender. Para tanto, o autor ressalta que é necessário que o jogo didático apresente um equilíbrio entre o lúdico e o educativo, para que o objetivo proposto para a atividade seja alcançado, em suas palavras o considera que,

Se uma dessas funções for mais utilizada que a outra, ou seja, se houver um desequilíbrio entre elas, provocaremos duas situações: quando a função lúdica for maior que a educativa, não temos mais um jogo educativo, mas somente o jogo. Quando temos mais a função educativa do que a lúdica, também não temos mais um jogo educativo, e sim um material didático, nem sempre divertido (SOARES, 2015, p. 46).

No ensino de Química, os jogos estão ganhando evidência, como recursos didáticos, aplicados no processo de ensino, e aprendizagem, de diversos conteúdos e seus conceitos. Por serem importantes recursos para aulas de química, os jogos são empregados nas aulas com diferentes objetivos, conforme destacado por Cunha (2012), os jogos podem,

a) proporcionar aprendizagem e revisão de conceitos, buscando sua construção mediante a experiência e atividade desenvolvida pelo próprio estudante; b) motivar os estudantes para aprendizagem de conceitos químicos, melhorando o seu rendimento na disciplina; c) desenvolver habilidades de busca e problematização de conceito; d) contribuir para formação social do estudante, pois os jogos promovem o debate e a comunicação em sala de aula; e) representar situações e conceitos químicos de forma esquemática, ou por meio de modelos que possam representá-los (CUNHA, 2012, p. 96).

Segundo Reganham e Parra (2016, p. 4) “[...], brincar favorece o desenvolvimento de capacidades de socialização, nas quais destacam-se as atividades de interação e de representação de papéis sociais, [...]". O jogo é, portanto, uma atividade livre e prazerosa (GARCEZ; SOARES, 2017), além de desenvolver habilidades sociais e afetivas nos estudantes envolvidos. Quando aplicados ao ensino em geral, e ao de química, contribuem com o processo de ensino e aprendizagem, nesse sentido, o objetivo desta pesquisa é o de investigar as contribuições da utilização de um jogo didático no Ensino do conteúdo de Radioatividade, em aulas de Química no 2º ano do ensino médio. 


\section{O Ensino e Aprendizagem de Radioatividade e os Jogos Didáticos}

A utilização de recursos metodológicos, diferentes do quadro negro e do giz na educação, têm se destacado nas pesquisas relacionadas aos diferentes processos de ensino, e aprendizagem. No ensino de química, a utilização de novos recursos metodológicos tem se tornado uma realidade e, isso deve-se ao fato de que este ensino é, quase sempre, tradicional, para Lima e seus colaboradores (2011): Vários estudos e pesquisas mostram que o Ensino de Química é, em geral, tradicional, centralizandose na simples memorização e repetição de nomes, fórmulas e cálculos, totalmente desvinculados do dia a dia, e da realidade, em que os alunos se encontram. A Química, nessa situação, torna-se uma matéria maçante e monótona, fazendo com que os próprios estudantes questionem o motivo pelo qual ela lhes é ensinada, pois a química escolar que estudam é apresentada de forma, totalmente, descontextualizada (LIMA, et al., 2011, p. 05).

A Química possui uma linguagem própria, constituída por símbolos, equações químicas e matemáticas, quase sempre ensinadas por meio da memorização. Esse ensino repetitivo, e desinteressante, contribui para a construção de uma visão distorcida da química entre os estudantes, principalmente, entre os do ensino médio. Para Silva e Guerra (2016),

[...] grande parte das dificuldades dos alunos em aprender química é devido ao modo como ela é apresentada aos alunos, que na maioria das vezes é importada como uma disciplina que necessita de memorização, o que torna chato para os alunos e acaba criando barreiras entre as disciplinas e os alunos (SILVA; GUERRA, 2016, p. 15).

No intuito de superar essa visão distorcida, o processo de ensino e aprendizagem em Química deve ser atrativo, motivador e interessante para o estudante. Contudo, alguns conteúdos, e seus conceitos, pouco aparecem nas aulas de química do ensino médio. Quando abordados, quase sempre é devido a sua visibilidade na mídia, ou suas aplicações sociais, como por exemplo, o conteúdo de Radioatividade. Para Moreis (2015, p. 22), "a radioatividade vem sendo abordada nos livros de química do ensino médio, de uma forma muito elementar, com poucas explicações, a-histórica, e sem contextualização dos fatos". A autora acredita que a maneira como esse conteúdo, e seus conceitos, são abordados em sala de aula, está limitando a discussão de fatos históricos importantes, além de abordar apenas conceitos básicos de química que envolvem o ensino de radioatividade. De acordo com Silva, Bezerra e Aquino (2016),

É importante ressaltar que a radioatividade não é um tema desconhecido para a maioria dos estudantes, pois eles já trazem, para sala de aula, conhecimentos prévios, principalmente, pela interação com os meios de comunicação. Desde os ataques às Cidades Japonesas de Hiroshima e Nagasaki, em 1945, que notícias sobre radioatividade são destaques na mídia, porém, quase sempre, com enfoque de destruição e morte, propiciando a criação de uma ideia errônea sobre o uso da radioatividade. Neste sentido, é importante que os professores elaborem estratégias de ensino que trabalhem o tema de forma mais contextualizada (SILVA; BEZERRA; AQUINO, 2016, p. o1).

É necessário que o professor compreenda a importância de incluir em suas aulas, sempre que possível, ferramentas didáticas alternativas, a fim de que estas colaborem com o processo de ensino e aprendizagem, proporcionando aulas contextualizadas e dinâmicas, que sejam significativas aos estudantes, e incentivem sua participação. Uma opção, frequentemente utilizada, são os jogos didáticos, os quais vêm se destacando como recurso mediador no processo formativo.

O desenvolvimento social proporcionou intensas transformações na tecnologia, na saúde, na ciência, e até mesmo na escola, mesmo que esta mantenha sua estrutura básica inalterável. Em meio a esse desenvolvimento social, e com a presença de novos recursos no cotidiano escolar, novas práticas pedagógicas são desenvolvidas pelos professores, no intuito de tornar o ensino significativo e contextualizado. Nesse sentido, professores de química têm inserido, em seu planejamento, o uso do lúdico como uma metodologia alternativa para o ensino dos conteúdos, e conceitos da área.

Os últimos anos foram marcados por um aumento na utilização de jogos, e atividades lúdicas, aplicadas ao ensino de química. Para Soares (2016), esse aumento é refletido na produção acadêmica 
(mestrado acadêmico, mestrado profissional e doutorado), em suas pesquisas o autor relata que, entre os anos de 2004 a 2016, "houve a produção de 21 trabalhos acadêmicos, diretamente, na temática de jogos e atividades lúdicas no ensino de química" (2016, p. 7). Para o autor, esse aumento se deve ao "fato de que os jogos, realmente, funcionam em sala de aula. É evidente que a alternativa, desde que bem planejada, teorizada e aplicada, funciona adequadamente" (SOARES, 2016, p. 8).

Utiliza-se jogos desde os primórdios, seja para o divertimento, ou para a interação com o mundo, há registros históricos da presença deste recurso muitos anos antes, na Roma e na Grécia Antiga (GARCEZ; SOARES, 2017). Platão, em seus manuscritos, fala da importância do "aprender brincando", e Aristóteles acreditava que os jogos poderiam ajudar as crianças nas tarefas a serem realizadas, já que elas, por meio da brincadeira, imitavam o que os adultos faziam. No século seguinte, a utilização dos jogos foi ampliada, com destaque ao emprego da imagem e dos sentidos, no processo de ensino e aprendizagem (KISHIMOTO, 1994).

É recorrente, nas pesquisas, a classificação dos jogos em educativo ou didático. Cunha (2012) diferencia, e define, os dois termos utilizados na classificação dos jogos aplicados ao contexto escolar, para a autora,

O primeiro envolve ações ativas e dinâmicas, permitindo amplas ações na esfera corporal, cognitiva, afetiva e social do estudante, ações essas orientadas pelo professor, podendo ocorrer em diversos locais. O segundo é aquele que está, diretamente, relacionado ao ensino de conceitos e/ou conteúdos, organizado com regras e atividades programadas, e que mantém um equilíbrio entre a função lúdica e a função educativa do jogo, sendo, em geral, realizado na sala de aula, ou no laboratório (CUNHA, 2012, p. 95).

De acordo com o as definições de Cunha (2012), ambos contribuem com a construção do conhecimento escolar, porém, os jogos educativos apresentam uma liberdade maior, quando comparados aos didáticos, já que podem ser realizados em ambientes não formais de ensino, enquanto os jogos didáticos, tradicionalmente, relacionam conceitos, e conteúdo, em um espaço específico de formação, a escola. "Um jogo didático, [...] é educativo, pois envolve ações lúdicas, cognitivas, sociais etc., mas nem sempre um jogo que é educativo, pode ser considerado um jogo didático" (CUNHA, 2012, p. 95).

Apesar de haver diferentes classificações, existe certa dificuldade em apresentar uma definição para o termo 'Jogo'. Entretanto, autores como Garcez e Soares (2017, p. 184), descrevem o jogo como "uma atividade livre, consciente, não-séria, exterior à vida habitual, com desinteresse material e natureza improdutiva, que possui finalidade em si mesma, prazer (ou desprazer), caráter fictício ou representativo, com limitação no tempo e no espaço, com regras explícitas e implícitas”. Contudo, quando um jogo é inserido no contexto escolar, com objetivo centrado na "aquisição de conhecimentos específicos sobre determinados conteúdos", ele torna-se jogo educativo formalizado (JEF) (CLEOPHAS; CAVALCANTI; SOARES, 2018, p. 39).

Os jogos educativos, formalizados, contribuem para o processo ensino e aprendizagem dos conceitos científicos, uma vez que são elaborados com uma "intencionalidade pedagógica" (CLEOPHAS, CAVALCANTI; SOARES, 2018, p. 39). Sua função é a de ensinar algum conceito ou conhecimento, de forma que a interação entre professor-estudante seja investigativa. Contudo, Santana e Rezende (2014) ressaltam que,

É importante enfatizar que não se deve ter uma visão reducionista de que a aprendizagem ocorra, apenas, pelo prazer que a atividade com jogos proporciona por si mesma. Ela deve ser compreendida como uma estratégia metodológica, orientada para que o estudante possa, ativamente, construir seu conhecimento (SANTANA; REZENDE, 2014, p. 147).

A participação do estudante deve ir além da memorização de conceitos e definições, da utilização de fórmulas e das respostas prontas, o jogo deve mobilizar diferentes conhecimentos, ser desafiador, estimulante, de forma que os estudantes participem ativamente de suas etapas, compreendendo seus objetivos, respeitando as regras e a participação dos colegas. O professor deve levar em consideração que, se durante o jogo "o estudante precisa enfrentar um problema e tomar uma decisão, ele necessitará selecionar e organizar informações, propor estratégias, o que acarretará a 
elaboração de hipóteses e identificação de variáveis, que são habilidades de alta exigência cognitiva" (SUART; SOUZA, 2018, p. 87-88).

O envolvimento, e a participação efetiva, dos estudantes com jogos didáticos, desenvolvem alguns efeitos e mudanças que refletem no comportamento dos estudantes, a saber:

a) a aprendizagem de conceitos, em geral, ocorre mais rapidamente, devido à forte motivação;

b) os alunos adquirem habilidades, e competências, que não são desenvolvidas em atividades corriqueiras;

c) o jogo causa no estudante uma maior motivação para o trabalho, pois ele espera que este lhe proporcione diversão;

d) os jogos melhoram a socialização em grupo, pois, em geral, são realizados em conjunto com seus colegas;

e) os estudantes que apresentam dificuldade de aprendizagem, ou de relacionamento com colegas, em sala de aula, melhoram sensivelmente o seu rendimento e a afetividade;

f) os jogos didáticos proporcionam o desenvolvimento físico, intelectual e moral dos estudantes;

g) a utilização de jogos didáticos faz com que os alunos trabalhem, e adquiram conhecimentos, sem que estes percebam, pois, a primeira sensação é a alegria pelo ato de jogar (CUNHA, 2011, p. 95-96).

Para Cunha (2012), os jogos possibilitam, não apenas, o desenvolvimento cognitivo do estudante, mas também, o social e cultural, construído a partir das relações com o outro, dentro do espaço formal de ensino.

\section{MATERIAIS E METÓDOS}

A metodologia abordada nesta pesquisa é de natureza qualitativa, pois os dados recolhidos são designados por qualitativos, o que significa riscos por menores descritivos relativamente a pessoas, locais e conversas, e de complexo tratamento estatístico (BOGDAN; BIKLEN, 1994, p.16). São, portanto, dados produzidos em um contexto natural, sem o intuito de se comprovar uma hipótese, uma vez que se busca compreender as diferentes perspectivas dos participantes, da pesquisa, a respeito da aplicação do jogo "Jornada Radioativa".

Trata-se de uma pesquisa qualitativa do tipo exploratória, cujo objetivo é o de "[...] proporcionar familiaridade com o campo de estudo" (FRANCO; DANTAS, 2017, p. 14846). Trata-se de uma pesquisa cujo planejamento "[...] permite a análise de vários aspectos relacionados com o fenômeno" estudado (OLIVEIRA, 2011, p. 20). O instrumento utilizado para a produção dos dados foi um questionário. Segundo Marconi e Lakatos (1996, p. 88), o questionário consiste em uma "[...] série ordenada de perguntas, respondidas por escrito, sem a presença do pesquisador”. Segundo Oliveira (2011, p. 37), o questionário permite "alcançar um maior número de pessoas, é mais econômico; a padronização das questões possibilita uma interpretação mais uniforme dos respondentes, o que facilita a compilação e comparação das respostas escolhidas, além de assegurar o anonimato ao interrogado".

No Quadro 1, foram relacionadas as questões do Questionário, que foi aplicado com objetivo de identificar o perfil socioeconômico, e de compreender acerca do conhecimento dos participantes da pesquisa, sobre radioatividade, mediante a aplicação de um Jogo Educativo Formalizado.

Quadro 1: Questionário aplicado aos participantes da pesquisa, após a aplicação do jogo "Jornada Radioativa".

\begin{tabular}{|l|}
\hline \multicolumn{1}{|c|}{ Questões do Questionário } \\
\hline Bloco 1 - Perfil Socioeconômico \\
\hline 2. Idade \\
\hline 3. Raçnero \\
\hline 4. Profissão pretendida \\
\hline \multicolumn{2}{|c|}{ Bloco 2 - Conhecimentos Sobre Radioatividade } \\
\hline
\end{tabular}




5. O que você sabe sobre Radioatividade?
6. Cite situações do cotidiano que podem ser explicadas a partir dos conceitos de radioatividade
7. Com suas palavras, diga o que é Radioatividade?
8. Nas suas aulas de Química, há aulas de experimentação e utilização de jogos didáticos?
9. O que você acha da utilização de jogos didáticos no ensino de química?
10. Para você, quais outros métodos poderiam ser utilizados para facilitar o aprendizado?
11. Você acha que o "Jornada Radioativa" facilitou o aprendizado do conteúdo?
12. Quais os pontos negativos do jogo "Jornada Radioativa"?

Fonte: Elaborado pelas autoras.

Utilizando-se da contextualização histórica, e dos conceitos de química, especificamente sobre radioatividade, elaborou-se o jogo "Jornada Radioativa". Esta atividade foi desenvolvida como parte das atividades práticas da disciplina de Estágio Supervisionado IV, cursada no $8^{\circ}$ período do curso de Licenciatura em Química, da Universidade Federal do Acre (UFAC), durante o ano de 2018. A proposta do jogo "Jornada Radioativa" baseia-se em um jogo tradicional de tabuleiro, para abordagem de um conteúdo selecionado, a fim de incitar nos estudantes uma atitude lúdica.

O jogo foi aplicado em duas turmas do 2o ano do Ensino Médio, e contou com a participação de 26 estudantes do colégio de aplicação (CAP), escola-campo própria da UFAC, para observação, e estágio para os cursos superiores de licenciatura desta Universidade. Primeiramente, os estudantes tiveram aulas expositivas-dialogadas, e resoluções de exercícios sobre o conteúdo, de radioatividade, com as professoras-licenciandas (estagiárias), para que depois fosse aplicado o jogo como recurso lúdico, a fim de reforçar a base teórica construída.

Para o jogo, as salas foram separadas em 4 grupos, com 3 ou 4 estudantes, conforme o número de alunos por turma, para cada partida. Ao final desta atividade lúdica, foi entregue o questionário supracitado, para que cada um dos estudantes participantes o respondesse. Foram utilizadas duas aulas de 50 minutos, em sequência, totalizando, em torno de, uma hora e trinta minutos de duração, sendo 20 minutos para organização dos estudantes em grupos, para a disputa, e explicação das regras do jogo, 6o minutos para o jogo e, 20 para a reorganização da sala, e aplicação do questionário.

Apesar de não haver sido submetido um projeto específico para o Comitê de Ética em Pesquisa, tomou-se o cuidado de informar, aos participantes, sobre os procedimentos éticos que seriam adotados durante todo o desenvolvimento da pesquisa, inclusive na aplicação do questionário. Os estudantes foram informados que sua participação seria voluntária, e que poderiam desistir de participar a qualquer momento, além disso, foram orientados a não identificarem com seus nomes o questionário, uma vez que não seriam identificados nas produções decorrentes dessa pesquisa.

\section{Elaborando o Jogo Jornada Radioativa}

O jogo é constituído por um tabuleiro; um dado; 5 piões-cientistas, e um conjunto de cartõesperguntas. Para a confecção, foram utilizados materiais de baixo custo e fácil acesso, como: cartolinas, cola, tesoura sem ponta, canetas hidrográficas, e folhas sulfite A4, com impressões dos símbolos, e da escrita, utilizados nas casas, e as imagens dos cientistas, como observado na Figura 1, a seguir:

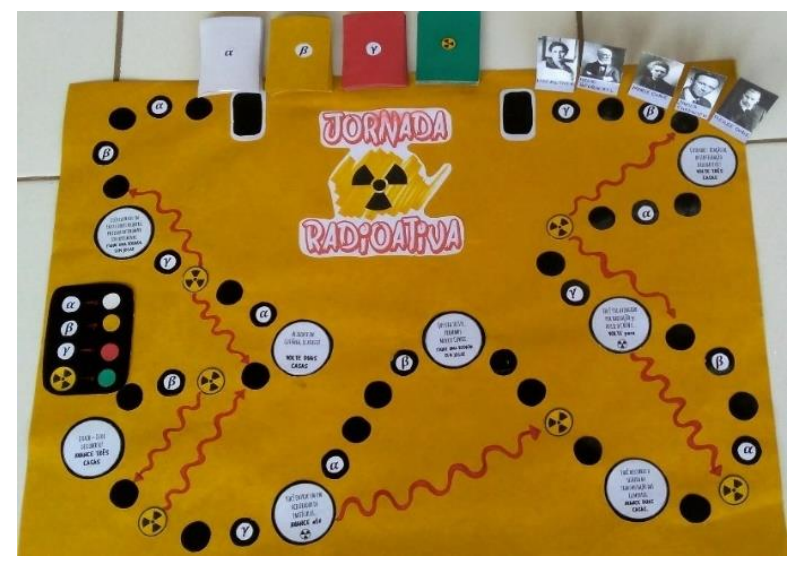

Figura 1: Peças e tabuleiro do jogo “jornada radioativa”. Fonte: Elaborada pelas autoras. 
No tabuleiro, há casas $\alpha, \beta$ e $\gamma$, que são correlacionadas às emissões radioativas, casas com o símbolo trifólio, o símbolo internacional da radiação, e casas de ações, que indicam atitudes variadas, que os jogadores devem ter no percurso da trilha, por exemplo "Que dia triste... perdemos Marie Currie. Fique uma rodada sem jogar", como pode ser visto na Figura 2, abaixo.

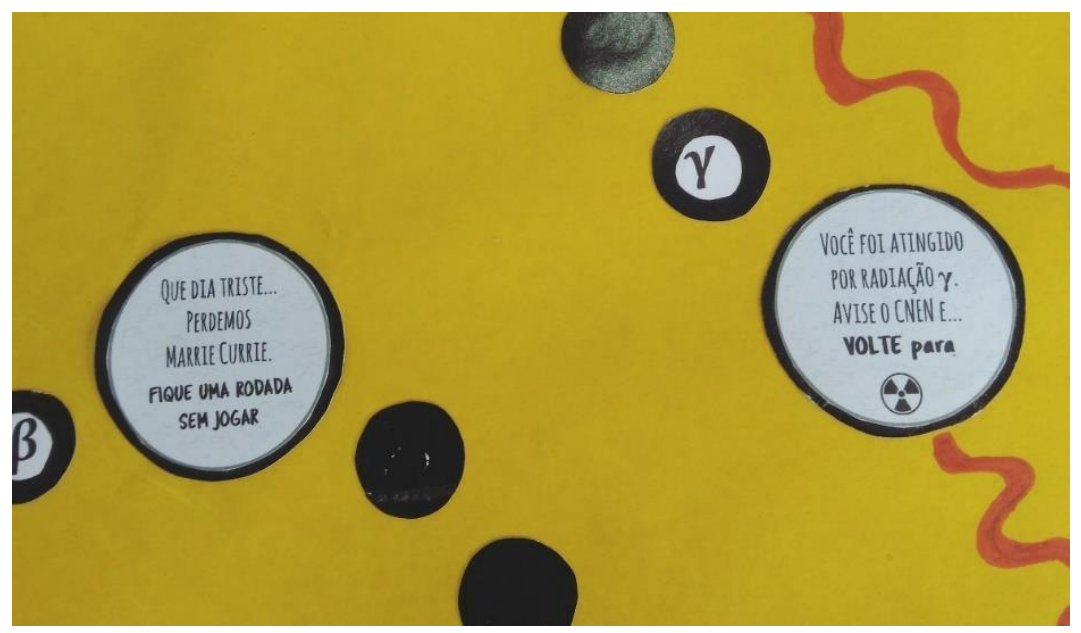

Figura 2: Algumas das casas do tabuleiro do jogo "jornada reativa”. Fonte: Elaborada pelas autoras.

Os piões-cientistas dos jogadores (Figura 3), são representados por alguns dos cientistas que deram contribuições, relevantes, através de suas pesquisas para a descoberta da radioatividade.

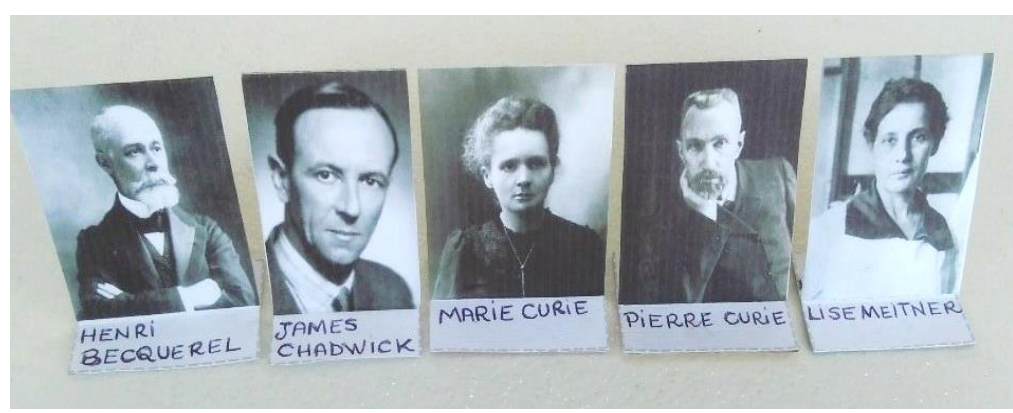

Figura 3: Piões-cientistas do jogo "jornada radioativa”. Fonte: Elaborada pelas autoras.

$\mathrm{O}$ jogo, também, possui cartões que se referem às perguntas a serem respondidas pelos jogadores (estudantes). Os símbolos das casas indicaram o tipo de cartão-pergunta, sendo as questões $\alpha, \beta$ e $\gamma$ de nível fácil, médio e difícil, respectivamente, todas relacionadas ao conteúdo abordado no jogo, como observamos na Figura 4, a seguir:

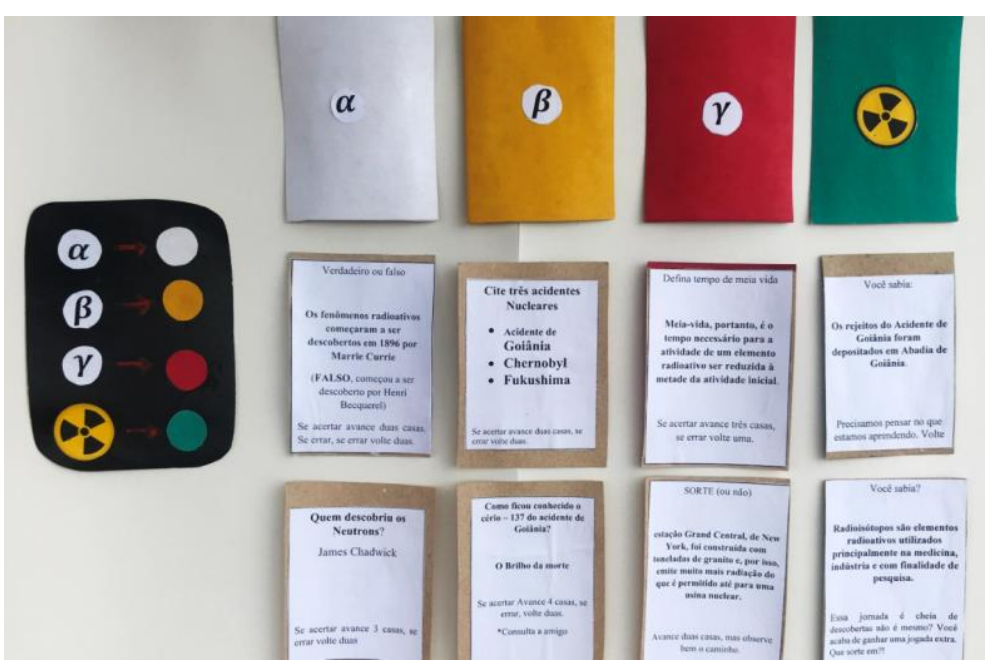

Figura 4: Alguns dos cartões-pergunta do jogo "Jornada Radioativa”. Fonte: Elaborada pelas autoras. 
Em alguns cartões-pergunta $\alpha, \beta$ e $\gamma$, existirão bônus, como por exemplo "Peça ajuda a um amigo", ou "pesquise a resposta". Os cartões-pergunta, com o símbolo trifólio, são cartas do tipo "Você Sabia", para incrementar conhecimento, ou contar fatos curiosos sobre a radioatividade, e indicam avançar ou retroceder casas. Em todas as categorias, também, há cartas de sorte ou azar, que dão oportunidade ao jogador de avançar (sorte), ou o fazem retroceder (azar) casas.

O jogo "Jornada Radioativa" pode ser jogado com 2 a 4 participantes, havendo possibilidade de ser jogado em duplas, trios ou grupos, desde que se tenha um representante, por equipe, para mexer o pião-cientista, e dar a resposta ao intermediário do jogo. Para melhor aproveitamento da atividade para o ensino, indicamos que sejam feitas equipes de até 5 estudantes. Neste caso, a intermediária foi uma das professoras-licenciandas (estagiária).

O objetivo do jogo "Jornada Radioativa" consiste em ter um primeiro jogador, ou grupo de jogadores (com seu cientista representativo), que chegue primeiro à casa FIM. O dado é lançado para determinar qual dos cientistas iniciará o jogo. Quem tirar o número mais alto, ganha o direito de iniciar, e seguirá em sentido horário. Para jogar, cada jogador, ou representante, lançará o dado, e andará o número de casas indicado pelo dado. Se a casa em que o pião-cientista parar houver um símbolo, um cartão-pergunta, correspondente ao símbolo, deverá ser puxado e respondido, ou realizada a ação solicitada. Se acertar a pergunta, andará o número de casas indicado no cartão, e se errar a resposta, deverá retroceder o número de casas indicado no cartão. O jogo assim procede, até que um pião-cientista chegue ao final do percurso do tabuleiro. Cabe ressaltar que não é necessário tirar o número exato, através do lançamento do dado, para andar o número de casas, e chegar ao fim do jogo. Por exemplo, se faltarem 4 casas para chegar à casa FIM, e o jogador, ou representante, tirar nos dados os números 4,5 ou 6 , será o ganhador da partida.

\section{RESULTADOS E DISCUSSÃO}

Durante as rodadas do jogo, os estudantes se mostraram muito interessados e concentrados, e a competição entre as equipes os motivou, ainda mais, a desenvolver a atividade. A competição observada durante a atividade foi estimulante e saudável, havendo cooperação entre os colegas de cada grupo, para conseguirem responder corretamente as perguntas. Foi possível perceber que a disputa incitava os estudantes a prestarem atenção, não só no jogo em si, mas, ainda mais, no conteúdo, pois almejavam o prêmio, a vitória. Sem o acerto, não havia avanço nas casas da trilha, logo, não se vencia.

Durante as discussões, percebeu-se uma troca de conhecimento muito rica entre os estudantes para determinar uma resposta, e muitas dúvidas foram esclarecidas. Ressaltamos que o "Jornada Radioativa" não é um jogo apenas de sorte-azar, ele requer atenção e habilidade, além de valorizar o conhecimento prévio, pois quanto mais os jogadores do grupo conhecem sobre o conteúdo abordado, discutem acerca da pergunta feita (interpretação textual), e cooperam entre si para chegar à resposta, maiores são as chances de vencer a partida.

Assim, a utilização do jogo mostrou ser um recurso educacional relevante para a aprendizagem, de fato, e efetivo para solidificação da base teórica construída, além de incrementar conhecimentos de fatos curiosos acerca do assunto. Para Soares (2013), processos de ensino e aprendizagem podem ocorrer de forma prazerosa e divertida, pois sempre que possível, o professor pode inserir no seu plano de trabalho estratégias que abordem os conteúdos, e conceitos químicos desta forma. Pois a "utilização de jogos ou atividades lúdicas, nas aulas de Química, podem instigar o interesse dos alunos, tornar o ensino mais dinâmico, auxiliar na construção, e compreensão de conceitos científicos, e assim, promover um aprendizado mais significativo" (SILVA; PIRES, 2020, p. 2).

Para a descrição e análise dos resultados do questionário aplicado, considerou-se unificá-los nas duas turmas participantes da pesquisa. A análise do perfil, socioeconômico, dos estudantes, destacou uma heterogenia entre os participantes, dos 26 , cerca de $84,6 \%$ possuíam 16 ou 17 anos, e os outros 15,4\% apresentaram variação entre 15 e 19 anos. Cerca de 57,7\% dos participantes são do sexo feminino, enquanto $42,3 \%$ são homens. Aproximadamente $30,8 \%$ dos participantes, se auto declararam "brancos", enquanto 69,2\%, "pardos". 
Os estudantes foram questionados sobre a carreira profissional por eles pretendida, dos 26 participantes, 7 relacionaram profissões ligadas à área da saúde, como: "Medicina", "Educação Física", "Psicologia" e "Nutrição", 6 participantes citaram "Direito" como profissão de interesse, 4 indicaram algum curso de "Engenharia", outros 4 participantes indicaram "Medicina Veterinária", e 1 se mostrou interessado em "Ciências Biológicas", indicando professor de Biologia, 1 participante citou como curso "Sistemas", e 3 estudantes, ainda, não haviam decidido por uma profissão.

A análise do perfil socioeconômico nos mostrou as condições dos estudantes pesquisados, enquanto a pretensão profissional indicou que os estudantes têm expectativas acadêmicas, mas não têm afinidade pela área de Ciências da Natureza, nem especificamente pela de Química. Estes dados podem ser correlacionados com os de 2018, da pesquisa do perfil dos estudantes com 15 e 16 anos, segundo o critério "alunos que esperam concluir, pelo menos, o ensino superior" do Programa Internacional de Avaliação de Estudantes (PISA, tradução de Programme for International Student Assessment), que é realizado a cada três anos pela Organização para a Cooperação e Desenvolvimento Econômico, OCDE (MAPA DA APRENDIZAGEM, 2019).

Segundo esta pesquisa, cerca de $53 \%$ dos estudantes, de nível socioeconômico baixo do Estado do Acre e $65 \%$ da Região Norte do Brasil, têm pretensão de conseguir diploma acadêmico. Ainda, no Brasil, cerca de $8,5 \%$ estudantes do sexo feminino, e $13 \%$ do masculino, possuem nível de aprendizado adequado em Ciências, o que pode ser uma das justificativas para o desinteresse da continuidade de estudos, em nível Superior, em cursos relacionados às Ciências da Natureza. Isso reforça a necessidade de inserir inovações metodológicas que despertem o interesse dos estudantes, e os impulsione para um aprendizado significativo, especialmente em Química, para que seja diminuída a dissociação entre os saberes e suas aplicações, inclusive no aspecto profissional, de forma a contribuir para a preparação de cidadãos prontos para a vida real.

Com relação aos conhecimentos sobre radioatividade, inicialmente foi questionado aos participantes da pesquisa: “O que você sabe sobre Radioatividade?”. As respostas foram compiladas no gráfico 1, como observado a seguir:

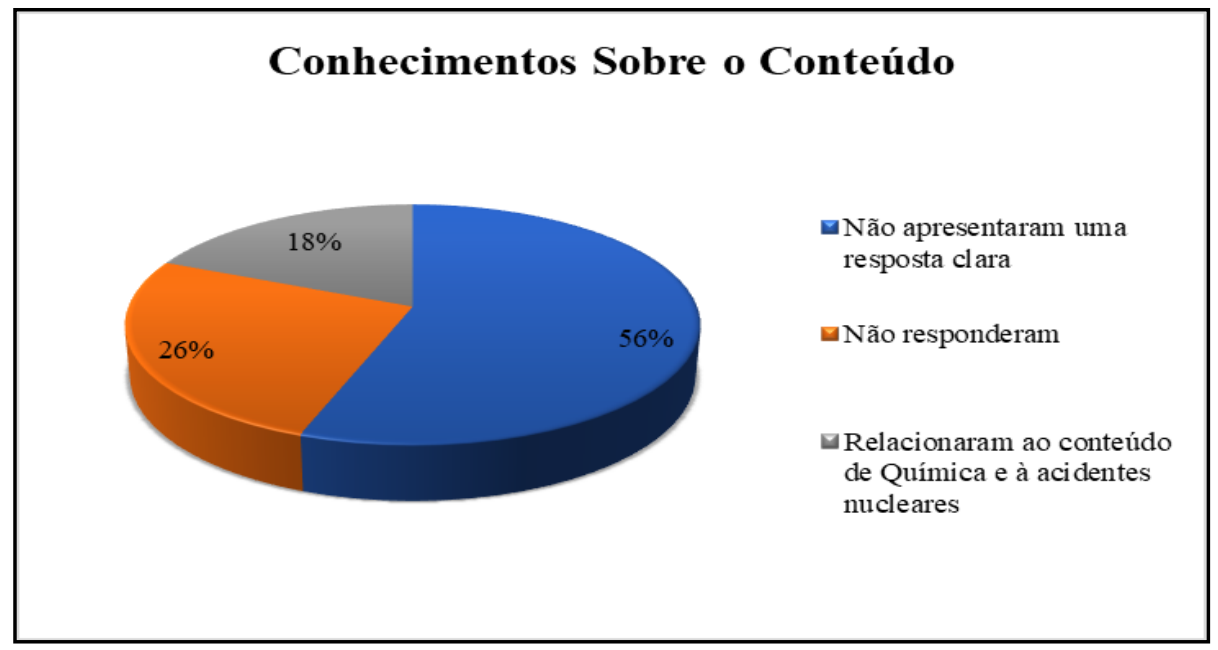

Gráfico 1: Conhecimentos sobre radioatividade. Fonte: Dados da pesquisa.

De acordo com o Gráfico 1, cerca de 56\%, dos 26 estudantes participantes da pesquisa, não sabiam explicar seus conhecimentos sobre Radioatividade. Eles apresentavam termos isolados, como na resposta do Estudante I, a seguir:

Estudante I: "Perigoso, Mata, Muita Energia”.

Os termos, na sua maioria, possuem relação direta com conceitos teóricos, e com discussões sobre a 'Radioatividade' abordadas durante a aplicação do Jogo. Cerca de $26 \%$ dos participantes, não responderam à questão, e outros $18 \%$ têm seus conhecimentos sobre radioatividade relacionados aos 
acidentes nucleares mais conhecidos, bem como seus efeitos no cotidiano social da época, além disso, eles relacionaram o termo à uma área de estudo da Química.

Em seguida, foi solicitado aos participantes: "Cite situações do cotidiano que podem ser explicadas a partir dos conceitos de radioatividade". Cerca de 56\% dos estudantes, mesmo depois de terem tido aula teórica, resolvido exercícios e jogado o "Jornada Radioativa" expressaram, através das respostas, não possuir domínio sobre o assunto, a ponto de darem uma resposta concisa para o que foi pedido. Percebe-se que a representação que eles possuem de Radioatividade está pautada, principalmente, no "Raio-X", principal resposta escrita pelos participantes da pesquisa. Outros participantes citaram a utilização de aparelhos eletrônicos, como "televisão", "celulares" e "computadores", percebe-se, a partir das respostas dos estudantes participantes, que eles não citam situações do cotidiano, como radiografia, esterilização de materiais, radioterapia e outros, mas reconhecem aparelhos que são de uso recorrente no cotidiano.

Ao confrontar os resultados apresentados, nessas duas questões, com a participação dos estudantes durante o jogo, percebe-se um distanciamento entre o que eles respondem no questionário, e a maneira como participaram, discutiram conceitos, e informações relacionadas ao conteúdo de Radioatividade durante o jogo. No momento de aplicação, os estudantes demonstraram domínio de conhecimentos e conceitos relacionados ao conteúdo, o que não fica visível nas respostas individuais do questionário. Possivelmente, esse desempenho, durante a aplicação do jogo, tem a ver com a relação social construída entre os estudantes nos grupos, já que, junto à equipe, os estudantes discutiam os conceitos necessários para chegarem à uma resposta, e um dos participantes era incumbido de responder pelo grupo.

Quando organizados em grupo durante a aplicação do jogo, os estudantes participantes acertavam a maioria das respostas, mas ao responderem individualmente os questionários, não demonstraram o mesmo domínio dos conhecimentos. Como ressalta Cunha (2012, p. 95) "d), os jogos melhoram a socialização em grupo, pois em geral são realizados em conjunto com seus colegas", promovendo principalmente, o desenvolvimento social. Outra possibilidade é a de que os estudantes tenham compreendido essa questão como uma pergunta de prova, cujo objetivo consistia em verificar o nível da aprendizagem dos estudantes, isso possivelmente resultou em um desconforto nos mesmos (surpresa e nervosismo), o que influenciou, negativamente, nas respostas nesta questão da pesquisa. De acordo com Fragelli (2015), mesmo havendo boa preparação com relação ao conteúdo abordado, há outros fatores limitantes no rendimento dos estudantes, que são o nervosismo, e a ansiedade, nos momentos de provas.

Em seguida, aos participantes da pesquisa foi perguntado: "Com suas palavras, diga o que é Radioatividade?”. De 26 , cerca de $38,46 \%$ não souberam responder, ou não responderam, o que é. Enquanto cerca de $61,53 \%$, dos 26 participantes da pesquisa, relacionaram a radioatividade à uma área da Química; como um fenômeno e uma situação histórica, como observado nas respostas a seguir:

Estudante B: "Radioatividade é a área que estuda raios radioativos, e produtos também";

Estudante C: "É um acidente químico".

Estudante X: "Estuda o processo dos átomos de transmitir radiação";

Estudante N: "É um fenômeno nuclear que acontece através dos átomos";

A partir das respostas observadas, é possível compreendermos que os participantes da pesquisa não possuem uma compreensão clara do que é radioatividade, deixando evidente que os conhecimentos estão em construção, e parte deles foi (re)construída, a partir da aula sobre Radioatividade e da aplicação do jogo "Jornada Radioativa", como por exemplo, na fala do Estudante $\mathrm{C}$, ao relacionar radioatividade com um "acidente químico", possivelmente se referindo ao acidente de Chernobyl, ou ainda sobre o acidente nuclear de Angra dos Reis, já que esses foram, por diversas vezes, citados pelas professoras-licenciadas durante a aula teórica.

Em relação ao uso do jogo e da experimentação, foi questionado aos estudantes: "Nas suas aulas de Química, há aulas de experimentação e utilização de jogos didáticos?". Segundo os estudantes participantes da pesquisa, a professora regente usa, além do livro didático adotado pela escola (Química Cidadã - Volume 2, que não possui nenhum capítulo que trate exclusivamente do conteúdo, e conceitos da radioatividade no volume 2), textos extras, slides e projeção de vídeos, bem como a 
experimentação em suas aulas. Cerca de $57,7 \%$, dos 26 participantes, afirmaram haver uso de jogos didáticos no cotidiano das aulas de Química. O que denota que o potencial do ensino, dessa forma, ainda pode ser mais explorado. Muitas vezes, este recurso lúdico não é utilizado devido ao jogo ser associado à brincadeira, e, realmente, se não for conduzido, adequadamente, não traz o efeito significativo esperado, a função lúdica se sobressai à educativa. Para Soares (2016, p. 8) "[...], desde que bem planejado, teorizado e aplicado" o jogo funciona adequadamente.

Na sequência, os estudantes foram indagados pela pergunta "O que você acha da utilização de jogos didáticos no ensino de química?”. Em suas respostas, afirmam que:

Estudante A: "Atividades como esta quebra o gelo de aula chata, facilita e permite a interação";

Estudante B: "É muito mais fácil e prazeroso aprender assim, brincando";

Estudante C: "Bem proveitoso, divertido, com bastante aprendizado";

Estudante D: "Acho que é uma maneira bem divertida de aprender mais".

Nas respostas apresentadas pelos estudantes, percebe-se que eles ressaltam a importância da utilização de metodologias alternativas, àquelas utilizadas em uma aula expositiva oral, confirmando o quanto se faz necessária a inovação, e a utilização de recursos que facilitem o aprendizado e o torne mais atrativo, deixando a aula mais prazerosa e divertida, aumentando as chances de se ter um ensino eficaz e significativo. De acordo com Cunha (2012, p. 96), "os jogos didáticos, levados à sala de aula, proporcionam aos estudantes modos diferenciados para a aprendizagem de conceitos, e desenvolvimentos de valores", a dinâmica e a interação, que a atividade proporciona, tornam o processo de ensino e aprendizagem reconhecido pelo estudante.

A inovação e diversificação às tradicionais aulas não são apenas necessárias, mas, também, desejadas pelos estudantes, quando indagados: "Para você, quais outros métodos poderiam ser utilizados para facilitar o aprendizado?", cerca de 61,5\%, dos 26 participantes, responderam “aulas práticas", e "jogos e brincadeiras", outros 19,2\%, citaram "filmes", "estudo de caso", e aproximadamente $19,2 \%$, disseram não saber responder. Uma das respostas foi "aulas mais animadas e professores mais animados" - Estudante K, o que sintetiza e expressa a necessidade de empregar mais emoção e diversão ao ensino, que somente o convencional ou tradicional, pautado apenas na aula expositiva dialogada, não é suficiente nesta era tecnológica e globalizada.

A questão seguinte era: "Você acha que o "Jornada Radioativa" facilitou o aprendizado do conteúdo?". Em suas respostas, os estudantes disseram que este jogo os ajudou na melhor compreensão do assunto, como observa-se nos excertos a seguir:

Estudante E: "Que show o jogo de hoje, ele tinha muitas informações, como uma revisão geral de tudo que foi estudado";

Estudante F: "Este jogo desperta a curiosidade, o interesse em buscar conhecimento, porque a gente quer ganhar, e pra ganhar tem que saber";

Estudante G: "Aprendi muito mais, porque é dificil a gente esquecer o que se aprende brincando, é bem melhor aprender por meio de um jogo";

Estudante H: "As perguntas do jogo fazem a gente pensar no conteúdo, o que faz a gente querer estudar de verdade, porque queremos ganhar, sensacional, eu amei!".

As respostas mostram que a utilização destas atividades lúdicas, na sala de aula, é eficaz e que o professor precisa estar preparado para tais inovações, não podendo mais se limitar apenas a um quadro, pincel, ou giz, e ao livro didático.

Ainda, em relação ao jogo, foi questionado aos estudantes: "Quais os pontos negativos do jogo "Jornada Radioativa”?". Suas respostas foram compiladas no Gráfico 2, a seguir:

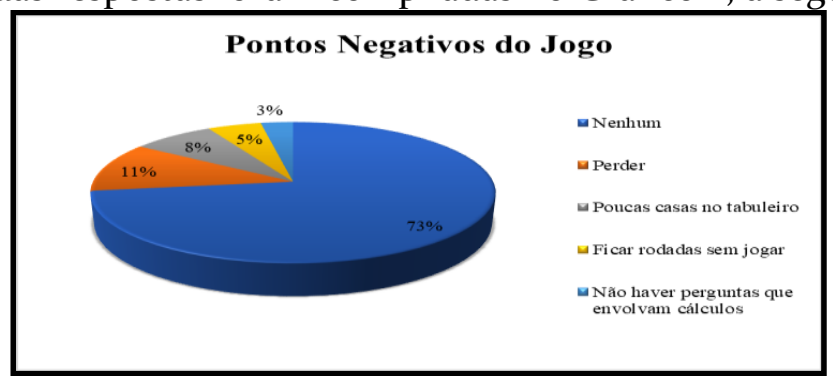

Gráfico 2: Respostas referentes aos pontos negativos do jogo "Jornada Radioativa”. Fonte: Dados da pesquisa. 
De acordo com as respostas apresentadas no gráfico 2, cerca de $73 \%$, dos 26 participantes, disseram não haver pontos negativos no jogo, cerca de $11 \%$ escreveram respostas relativas a perder a disputa, como observado a seguir:

Estudante H: "que eu não ganhei".

A resposta do Estudante $\mathrm{H}$ denota a frustração, dos participantes, diante de uma situação na qual não obtiveram o que desejavam. Nesse sentido, o jogo didático competitivo é importante para trabalhar o desenvolvimento de habilidades, e competências, relativas à convivência em sociedade, e à cidadania.

Com base nos resultados apresentados, é preciso ensinar os conceitos do conteúdo de Radioatividade sob uma perspectiva contextualizada, para estimular que os estudantes desenvolvam um olhar mais crítico e reflexivo sobre este tema, assim como instruí-los acerca da real significância, e diferenciação, dos tipos de radiações, e suas aplicações no cotidiano. Nesse sentido, a utilização de atividades lúdicas configura-se como um recurso eficaz a ser inserido na sala de aula.

Dessa forma, a função educativa do jogo "Jornada Radioativa" se mostrou bem eficaz, assim como a função lúdica. Por ser uma atividade lúdica, naturalmente, desperta o interesse dos estudantes para a ação desenvolvida, o que induz resultados positivos, tanto no aspecto disciplinar para revisão de conceitos abordados na aula teórica, quanto para o desenvolvimento socioemocional, e cooperativo, dos estudantes participantes desta atividade. Ressalta-se, ainda, que a proposta de jogo apresentada nessa pesquisa pode, também, ser utilizada em espaços não formais de ensino, como por exemplo, em gincanas, e ainda assim ser legitimada com uma atividade lúdica educacional.

\section{CONSIDERAÇÕES FINAIS}

Os jogos, didáticos ou não, naturalmente possibilitam o desenvolvimento de habilidades e relações, sejam elas sociais ou afetivas, dessa forma, eles foram se configurando como um recurso importante em diferentes contextos sociais, especialmente na escola. Nesse sentido, ao retornarmos ao objetivo desta pesquisa, que é o de investigar as contribuições da utilização de um jogo didático para revisão de conceitos no Ensino do conteúdo de Radioatividade, em aulas de Química no 2º ano do Ensino Médio, percebemos que o jogo "Jornada Radioativa" entusiasmou os estudantes durante a atividade. E é este entusiasmo, por sua vez, que facilita a apropriação do protagonismo no processo de aprendizagem, já que a construção de saberes e compreensões, acerca do conteúdo, ocorre de modo espontâneo e descontraído.

Além disso, a aplicação do jogo despertou a atenção dos estudantes, já que esta atividade lúdica trouxe ineditismo ao contexto formal deles. Quadro este em que a rotina em sala de aula é, quase sempre, acompanhada pela falta de motivação, decorrente, muitas vezes, da ausência de dinamicidade, e do tradicionalismo presente em aulas de Química. Durante a aplicação do jogo, pôde-se perceber interações socioafetivas, e colaborativas entre os estudantes, principalmente entre os de cada grupo, o que contribui para o desenvolvimento das competências socioemocionais, estando em consonância com os itens 8, 9 e 10 das competências gerais da educação básica, apresentadas no texto do documento da Base Nacional Comum Curricular (BRASIL, 2018).

O jogo "Jornada Radioativa" possibilitou uma interação entre os estudantes participantes e as professoras-licenciandas, permitindo que discutissem conceitos e informações diante do desafio que se apresentava em cada jogada. Essa participação espontânea, e ativa, dos estudantes foi mobilizada pelo interesse em acertar as perguntas para vencer o jogo, sendo notório que a atividade constituiu uma importante ferramenta para o desenvolvimento da cooperação, e da tolerância à frustração, ou seja, lidar com a competitividade de forma estimulante e saudável.

Não podemos garantir que o jogo "Jornada Radioativa" foi o principal responsável no processo de ensino e aprendizagem dos conceitos abordados, mas os resultados indicam que possibilitou discussões capazes de contextualizar os conhecimentos científicos, relacionados à radioatividade, com os conhecimentos cotidianos dos estudantes participantes da pesquisa. Dessa forma, o "Jornada 
Radioativa" pode ser considerado um jogo educativo formalizado, que facilita o ensino de radioatividade, proporcionando aprendizagem através da contextualização histórica, e revisão de conceitos, além de viabilizar um ensino integral e significativo.

\section{REFERÊNCIAS}

BOGDAN, R.; BIKLEN, S. Investigação Qualitativa em Educação: uma introdução à teoria e aos métodos. Tradução: Maria João Alvez; Sara Bahia dos Santos e Telmo Mourinho Baptista. Porto Editora. 1994.

BRASIL. Ministério da Educação. Base Nacional Comum Curricular. Brasília, 2018.

CLEOPHAS, M. G.; CAVALCANTI, E. L. D.; SOARES, M. H. F. B. Afinal de Contas, É Jogo Educativo, Didático ou Pedagógico no Ensino de Química/Ciências? Colocando os Pingos nos "Is". In: CLEOPHAS, M. G.; SOARES, M. H. F. B. (Orgs.). Didatização Lúdica no Ensino de Química/Ciências: teorias de aprendizagem e outras interfaces. São Paulo: Editora Livraria da Física, 2018.

CUNHA, M. B. Jogos no Ensino de Química: Considerações Teóricas para sua Utilização em Sala de Aula. Revista Química Nova na Escola. Vol. 34, n. 2, p. 92-98, 2012.

FRAGELLI, R. R. Trezentos: aprendizagem ativa e colaborativa como uma alternativa ao problema da ansiedade em provas. Revista Eletrônica Gestão \& Saúde. Vol. 6, Supl. 2, p. 860-872, 2015.

GARCEZ, E. S. C.; SOARES, M. H. F. B. Um Estudo do Estado da Arte Sobre a Utilização do Lúdico em Ensino de Química. Revista Brasileira de Pesquisa em Educação e Ciências. Vol. 17, n. 1, p. 183-214, 2017.

KISHIMOTO, T. M. O Jogo e a Educação Infantil. São Paulo: Pioneira, 1994.

LAPA, W. P. F. M.; SANTOS, W.P. Os Jogos e Outras Atividades Lúdicas no Contexto Educacional: o que é preciso para proporcionar atividades que tenham rigor educativo? In: LAPA, W. P. F. M.; SILVA; J. C. S. (Orgs.). Jogos no Ensino de Química: fundamentos e aplicações. Curitiba: CRV, 2018.

LIMA, E.C.; MARIANO, D. G.; PAVAN, F. M.; LIMA, A.A.; ARÇARI, D.P. O uso de jogos lúdicos como auxílio para o ensino de química. Revista Educação em Foco. n. 11, p. 1-15, 2011.

LOPES, M. D. B. A. Utilização de Jogos e Atividades Lúdicas como Auxílio no Ensino de Química. 2019. 63 p. Monografia (graduação) - Instituto Federal de Educação, Ciência e Tecnologia Goiano, Urutaí, 2019.

MARCONI, M. A; LAKATOS, E. M. Técnicas de pesquisa: planejamento e execução de pesquisas, amostragens e técnicas de pesquisas, elaboração e interpretação de dados. 3.ed. São Paulo: Atlas, 1996.

MAPA DA APRENDIZAGEM. PISA 2018. Disponível em: <http://mapadaaprendizagem.com.br/>. Acesso em o6 dez. 2020.

MOREIS, C. S. A Radioatividade e o Ensino de Química: um tema para debate. In: XVI Semana da Educação e VI Simpósio de Pesquisa e Pós-graduação em Educação - Desafios Atuais para a Educação. 2015. Londrina. Anais... Londrina: UEL, 2015, p. 21-25.

OLIVERIA, M. F. Metodologia Científica: um manual para a realização de pesquisas em administração. Catalão: UFG, 2011.

REGANHAM, M. B.; PARRA, C. R. O Lúdico como Mediador para o Desenvolvimento das Competências Socioemocionais na Escola. Psicologia.PT, p.1-14, 2016.

SANTANA, E. M.; REZENDE, D. B. Ludicidade, Atividades Lúdicas e Jogos como Instrumentos Mediadores da Aprendizagem de Ciências Naturais. In: SANTANA, E. M.; SILVA, E. L. (Orgs.). Tópicos em Ensino de Química. São Carlos: Pedro \& João Editores, 2014.

SANTOS, W. L. P.; MÓL, G. S.; DIB, S. M. F.; MATSUNAGA, R. T.; SANTOS, S. M. O.; CASTRO, E. N. F.; SILVA, G. S.; FARIAS, S. B. Química cidadã. Vol. 2, 3ª ed., São Paulo: AJS, 2016.

SILVA, A. S. F; BEZERRA, T. B. M. S; AQUINO, K. A. S; Estratégia Para o Ensino de Radioatividade na Perspectiva de uma Aprendizagem Significativa: Um Estudo após um Potencial Período de Obliteração.

Anais... Revista Conedu, v. 1, p. 1-10, 2016. 
SILVA, A. T. O.; PIRES, D. A. T. Gincana das Funções Inorgânicas: uma proposta lúdica para as aulas de Química. Revista Eletrônica Ludus Scientiae. Vol. 4, n. 1, p. 17, 2020.

SILVA, P. S. S.; GUERRA, E. C. S. Jogos Didáticos Como Ferramenta Facilitadora no Ensino de Química. 2016. 32 p. Trabalho de Conclusão de Curso (Graduação) - Instituto Federal de Educação, Ciência e Tecnologia de Goiás - Campus Inhumas, Inhumas, 2016.

SOARES, M. H. F. B.; Jogos e Atividades Lúdicas para o Ensino de Química. 2a. Edição. Goiânia: Kelps, 2015.

SOARES, M. H. F. B. Jogos e Atividades Lúdicas no Ensino de Química: uma discussão teórica necessária para novos avanços. Revista Debates em Ensino de Química. Vol. 2, n. 2, p. 5-13, 2016.

SUART, R. C.; SOUZA, J. A. Jogos Didáticos no Ensino de Química para a Promoção de Habilidades Cognitivas. In: CLEOPHAS, M. G.; SOARES, M. H. F. B. (Orgs.). Didatização Lúdica no Ensino de Química/Ciências: teorias de aprendizagem e outras interfaces. Editora Livraria da Física, São Paulo 2018.

VIEIRA, A. S. Uma Alternativa Didática às Aulas Tradicionais: o engajamento interativo obtido por meio do uso do método Peer Instruction (Instrução Pelos Colegas). 2014. 234 p. Dissertação (Mestrado em Ensino de Física) - Universidade Federal do Rio Grande do Sul. Porto Alegre, 2014.

Maiane França de Sales: Licenciada em Química pela Universidade Federal do Acre (UFAC). Durante a graduação participou como Bolsista do Programa Institucional de Iniciação à Docência - PIBID Química, foi monitoria das disciplinas, Instrumentação para o Ensino de Química II e Química Orgânica Experimental II. Atualmente cursa Técnico e Interprete de Libras no Instituto Federal do Acre (IFAC).

E-mail: fsmaiane@gmail.com

Janaina Santos da Silva: Graduanda em Licenciatura em Química pela Universidade Federal do Acre (UFAC), campus Rio Branco. No período de 08/2016 A 02/2018, participou como bolsista do Programa Institucional de Bolsas de Iniciação à Docência-PIBID/Química pela UFAC.

E-mail: janasantosdasilva@gmail.com

Shirani Kaori Haraguchi: Professora Adjunta na Universidade Federal do Acre. Possui graduação em Química Bacharelado pela Universidade Estadual de Maringá (2005) e mestrado em Química na área de Síntese de Compostos Orgânicos pela Universidade Estadual de Maringá (2008). Doutorado pela Universidade Estadual de Maringá na área de Físico-química em Química de Polímeros. Complementação pedagógica para Licenciatura em Química (2019) pela Universidade Cruzeiro do Sul. Tem experiência na área de Química Orgânica e Físico-Química. Atualmente, é professora e pesquisadora em temáticas relacionadas à Química com ênfase em Ensino de Química, Materiais Didáticos e Formação Inicial e Continuada de Professores.

E-mail: skharaguchi@gmail.com

Gahelyka Aghta Pantano Souza: Professora Assistente na Universidade Federal do Acre (UFAC). Doutoranda em Educação pela Universidade Federal do Paraná (UFPR). Mestre em Educação pela Universidade Federal do Mato Grosso (UFMT). Licenciada em Química pela Universidade Federal do Mato Grosso (UFMT). Vice-líder do Núcleo de Ensino e Pesquisa em Química (NEPQ/UFAC) e Coordenadora do Laboratório de Ensino e Pesquisa em Química (LEPQ/UFAC). Atualmente, é professora no curso de Licenciatura em Química da UFAC na área de Ensino de Química e Coordenadora da Residência PedagógicaQuímica. Tem experiência na área de Química e Ensino de Química com ênfase em Materiais Didáticos e Formação Inicial e Continuada de Professores.

E-mail: gahelyka@outlook.com 